\title{
Surgical reconstruction techniques for mitral valve insufficiency from lesions with restricted leaflet motion in infants and children
}

\author{
Eva Maria Delmo Walter, MD, MS, PhD, Takeshi Komoda, MD, PhD, Henryk Siniawski, MD, PhD, and \\ Roland Hetzer, MD, PhD
}

Objectives: We report our 23-year experience with leaflet and annular remodeling techniques in infants and children with congenital mitral valve insufficiency from lesions with restricted leaflet motion (type III).

\begin{abstract}
Methods: A review of the medical records, including follow-up echocardiographic studies of 49 children, aged 20 days to 14 years, was performed. These children were divided into age groups of 0 to $<1$ year $(\mathrm{n}=4$; mean age, $3.2 \pm 1.2$ months), 1 to 5 years $(\mathrm{n}=17$; mean age, $2.8 \pm 1.6$ years $)$, and older than 5 to 15 years $(\mathrm{n}=28$; mean age, $12.3 \pm 2.5$ years). All had severe mitral insufficiency from type III Carpentier's functional classification of mitral valve lesion. Restricted leaflet motion was secondary to commissural fusion in 17 children, thickened leaflets in 9 , short chordae in 6 , matted chordae in 2 , papillary muscle hypoplasia in 3 , a parachute valve in 11, and a hammock valve in 1 . Various repair strategies were applied.
\end{abstract}

Results: The perioperative course was unremarkable. The mean follow-up duration was $11.5 \pm 1.8$ years. A 2-year-old patient with a parachute valve underwent mitral valve replacement 2 years after the initial repair. She died 8 years later of noncardiac causes. The freedom from reoperation rate was $100 \%$ at 30 days and 1 year and $97.9 \%$ at $5,10,15$, and 20 years. The actuarial survival rate was $100 \%$ at 30 days, 1 year, and 5 years and $95.96 \%$ at 10,15 , and 20 years.

Conclusions: Mitral valve reconstruction of congenital mitral insufficiency from restricted leaflet motion in infants and children using various modified repair techniques tailored to the presenting valve morphology can be successfully performed in children with excellent long-term results. ( $\mathrm{J}$ Thorac Cardiovasc Surg 2012;143:S48-53)

Mitral valve (MV) reconstruction in infants and children has been, and will, always, remain a challenge owing to the great variability of the MV lesions and the uncertain effect that growth will have on the MV and subvalvar apparatus. Because congenital MV insufficiency (MI) from restricted leaflet motion is clinically important, although a rare entity, various repair techniques and results have been reported. ${ }^{1-6}$ However, the limited durability of repair has been a major setback. With meticulous intraoperative assessment of valve morphology and appropriate selection of the surgical strategy, we believe the repair can be longlasting. In our institution, MV repair is the preferred technique for any type of mitral disease in childhood. The repair allows for valve growth along the anterior leaflet annulus, ${ }^{7,8}$

Department of Cardiothoracic and Vascular Surgery, Deutsches Herzzentrum Berlin, Berlin, Germany.

Disclosures: Eva Maria Delmo Walter, Takeshi Komoda, Henryk Siniawski, and Roland Hetzer have nothing to disclose with regard to commercial support.

Presented at The American Association for Thoracic Surgery Mitral Conclave, New York, New York, May 5-6, 2011.

Received for publication May 16, 2011; revisions received Sept 29, 2011; accepted for publication Oct 20, 2011; available ahead of print Dec 15, 2011.

Address for reprints: Eva Maria Delmo Walter, MD, MS, PhD, Deutsches Herzzentrum Berlin, Augustenburger Platz 1, Berlin 13353, Germany (E-mail: delmo-walter@dhzb.de).

0022-5223/\$36.00

Copyright (c) 2012 by The American Association for Thoracic Surgery doi:10.1016/j.jtcvs.2011.10.033 provides no anticoagulation, and offers no thrombotic risk. This is best achieved by a spectrum of repair techniques tailored to the presenting lesion. We do not use any prosthetic material, and we stabilized our repair with untreated autologous pericardial strips. We report our 23-year experience with leaflet and annular remodeling techniques in infants and children with congenital MI from lesions with restricted leaflet motion.

\section{PATIENTS AND METHODS}

The institutional review board approved our study and waived the need for patient consent.

\section{Patients}

From January 1987 to December 2010, 49 children, aged 20 days to 14 years, underwent MV repair for severe MI from restricted leaflet motion (type III Carpentier's functional classification). Of these patients, 16 underwent surgery from 1987 to 1997, 21 from 1998 to 2008, and 8 patients from 2008 to 2010. These children were divided into age groups as follows: 0 to younger than 1 year $(\mathrm{n}=4$; mean age, $3.2 \pm 1.2$ months); 1 to 5 years $(\mathrm{n}=17$; mean age, $2.8 \pm 1.6$ years $) ;>5$ to 15 years $(\mathrm{n}=28$; mean age, $12.3 \pm 2.5$ years). The restricted leaflet motion with normal papillary muscles (type IIIA) was secondary to commissural fusion in 17 children, thickened leaflets in 9, short chordae in 6, and matted chordae in 2 . In those with restricted leaflet motion owing to abnormal papillary muscles (type IIIB), 3 had papillary muscle hypoplasia, 11 had parachute valve, and 1 had hammock valve. All patients were in New York Heart Association class III. No one had pulmonary hypertension. Their demographic profile is listed in Table 1. Echocardiograms were taken perioperatively and serially during follow-up. 


\section{Abbreviations and Acronyms \\ $\mathrm{MV}=$ mitral valve \\ MI $=$ mitral valve insufficiency}

\section{Echocardiographic Evaluation}

All 49 children and adolescents underwent a complete two-dimensional echocardiographic examination before surgery, at discharge from the hospital, and at a series of follow-up visits. Mitral insufficiency was quantified by measurement of both the regurgitation volume and the regurgitant jet. ${ }^{9}$ Using the color-Doppler flow studies, quantification of mitral regurgitation is undertaken by measurement of the differences between the mitral stroke and aortic stroke volume. The phenomenon of proximal isovelocity flow area, which corresponds to anatomic leakage, is used to measure the regurgitant volume know as proximal flow convergence. A regurgitation volume of $<30 \mathrm{~mL}$ indicates mild regurgitation, 30 to $59 \mathrm{~mL}$ moderate, and $>60 \mathrm{~mL}$, severe regurgitation. Using the regurgitant fraction, the severity of regurgitation was quantified as follows: none, $0 \%$; mild, less than $20 \%$; moderate, $20 \%$ to $40 \%$; moderate to severe, $40 \%$ to $60 \%$; and severe, exceeding $60 \%$. Generally speaking, the proximal isovelocity area and distal jet area, which are both measures of the leakage area of the MV in Doppler studies, virtually define regurgitation. Preoperatively, 38 patients had moderate to severe MI (grade III) and 11 had severe (grade IV) MI. All lesions with restricted leaflet motion, including parachute and hammock valves, had accompanying annular dilation. Parachute valves although primarily stenotic, had a poorly developed anterior leaflet $(\mathrm{n}=6)$ and short chordae $(\mathrm{n}=5)$ in addition to the annular dilation $(\mathrm{n}=11)$, making them incompetent. Figure 1 shows the preoperative and postoperative echocardiogram of a patient with a parachute valve and MV regurgitation. Likewise, the hammock valve, also primarily a stenotic lesion, had an associated shortened chordae tendinae and annular dilation, resulting in valve incompetence.

Preoperative echocardiographic assessment of the inflow gradient with continuous-wave Doppler measurements showed a mean of $1.8 \pm$ $0.32 \mathrm{~mm} \mathrm{Hg}$.

\section{Surgical Technique}

MV repair was performed through a median sternotomy under cardiopulmonary bypass and moderate systemic hypothermia. Antegrade intermittent cold crystalloid cardioplegia with topical hypothermia was used for myocardial protection. Before aortic and bicaval cannulation, the pericardium was opened longitudinally and a strip of pericardium was prepared free from adipose and extrapleural tissue and left untreated. Through a left atriotomy along the interatrial groove, the annulus, leaflets, chordae tendinae, and papillary muscles were exposed and meticulously inspected to determine the precise nature of the lesion, with particular attention given to the leaflet motion, position of the papillary muscles, and annulus. Leaflet coaptation was assessed with a forceful injection of saline with a bulb syringe through the valve. Using a nerve hook, the coaptation of the anterior and posterior leaflet with regard to the presence of sufficient tissues along the coaptation plane was assessed. ${ }^{10}$ After confirming that leaflet coaptation was restricted, giving rise to MV incompetence, the valve diameter was assessed with a Ziemer-Hetzer valve sizer (Fehling Instruments GmbH \& Co KG, Karlstein, Germany). The nomogram published by Rowlatt and colleagues ${ }^{11}$ is helpful in determining the normal valve diameter for a specific body surface area.

Various repair techniques were used according to the cause of the restricted leaflet motion and presenting valve morphology. The suture used for repair in children was 5-0 to 7-0 polypropylene, according to age. Pledgets and annular reinforcement strips from untreated autologous pericardium were also used.

In newborns and infants with a severely dilated annulus, this was best repaired with Kay-Wooler annuloplasty performed by shortening the segments of the posterior annulus next to both trigones, modified by using pledgets of untreated autologous pericardium (Hetzer's technique). ${ }^{10,12}$ This repair resulted in shortening of the posterior annulus (Figure 2, A).

For annular dilation in children and adolescents, this was repaired using a modified Paneth-Hetzer technique ${ }^{10,11}$ by a running suture along the posterior annulus from both trigones to the middle section, tied over a Ziemer-Hetzer valve sizer to prevent narrowing of the valve orifice. Both sutures were passed onto an untreated autologous pericardial strip attached from the midsegment toward the trigones. Continuous suture was anchored to the autologous pericardial pledget and previously placed trigonal suture and tied firmly, taking care to avoid additional narrowing of the orifice (Figure 2, B). The degree or extent of shortening was chosen to effect a good leaflet coaptation according to the calculated weight-related valve size.

Shortening the posterior annulus produced wide and even coaptation, in such a way that when the anterior mitral leaflet closes, the border between the smooth and rough surface of the anterior leaflet forms the closure line, without folding. Leaflet coaptation was tested by forceful injection of saline with a bulb syringe through the valve, looking for any residual regurgitation.

In children with fused commissures, commisurotomy was done on both the anterolateral and posteromedial commissures. Division and splitting of

TABLE 1. Demographic profile of 49 children with congenital mitral valve insufficiency from restricted leaflet motion, according to age group

\begin{tabular}{|c|c|c|c|}
\hline \multirow[b]{2}{*}{ Variable } & \multicolumn{3}{|c|}{ Age group } \\
\hline & $0-<1$ yr $(n=4)$ & $1-5$ yr $(n=17)$ & $>5-15 \mathrm{yr}(\mathrm{n}=28)$ \\
\hline \multicolumn{4}{|l|}{ Age } \\
\hline Mean & $3.2 \pm 1.2 \mathrm{mo}$ & $2.8 \pm 1.6 \mathrm{yr}$ & $12.3 \pm 2.5 \mathrm{yr}$ \\
\hline Median & $3 \mathrm{mo}$ & $1.8 \mathrm{yr}$ & $10.3 \mathrm{yr}$ \\
\hline Range & $20 \mathrm{~d}-8 \mathrm{mo}$ & $1-4 \mathrm{yr}$ & $8-14 \mathrm{yr}$ \\
\hline \multicolumn{4}{|c|}{ Restricted leaflet motion with normal papillary muscles } \\
\hline Fused commissures & 2 & 2 & 13 \\
\hline Thickened leaflets & 1 & 3 & 5 \\
\hline Short chordae & 1 & 1 & 4 \\
\hline Matted chordae & 1 & 1 & 1 \\
\hline \multicolumn{4}{|c|}{ Restricted leaflet motion with abnormal papillary muscles } \\
\hline Papillary muscle hypoplasia & - & 2 & 1 \\
\hline Parachute valve & - & 8 & 3 \\
\hline Hammock valve & - & - & 1 \\
\hline
\end{tabular}




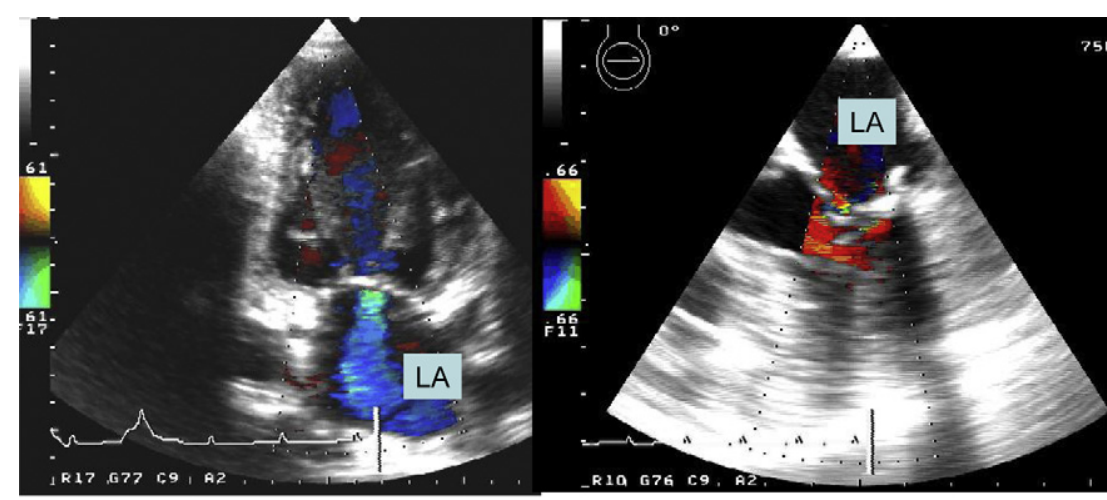

A

B

FIGURE 1. A, Chamber view of preoperative mitral regurgitation in parachute valve taken in systole. B, Postoperative transesophageal echocardiogram of same patient taken in systole.

papillary muscles were done in patients with short and matted chordae. In both aforementioned procedures, stabilization of the posterior annulus with autologous pericardial strip (modified Paneth-Hetzer plication plasty) ${ }^{10,12}$ was performed.

The hammock valve was dysplastic with shortened chordae directly inserted in a muscular mass of the posterior left ventricular wall, resulting in tethering of both leaflets, associated with annular dilation, making the valve predominantly incompetent. In the absence of any papillary muscle, a suitably thick part of the posterior left ventricular wall carrying the rudimentary chordae was carved off the wall (Figure 2, $C$, parts $a$ and $b$ ). Next, one must ensure that both the remaining left ventricular wall and the "new papillary muscles" maintain sufficient muscle thickness to perform their function (Figure 2, C, part c). ${ }^{12}$

The parachute valve has the usual two MV leaflets and commissures, but all the chordae tendinae cluster into one major papillary muscle. It presents as a funnel-type structure with some distinct fibrous lines at the sites of the commissural fusion. In 6 patients, the anterior leaflet was poorly developed, the chordae tendinae were shortened in 5, and all had annular dilation. These findings made the valve predominantly incompetent.

The most appropriate site for leaflet-splitting incisions was defined on both sides from the common papillary muscles toward the "assumed" trigones (commisurotomy and fenestration, Figure 2, D, parts $a$ and $b$ ). These incisions were extended into the body of the papillary muscle that was then split toward its base, ensuring sufficient thickness of both new "papillary muscle heads" (Figure 2, D, parts $c-e$ )..$^{12}$

The degree and extent of incision, commissurotomy, and fenestration was determined by measurement with a Ziemer-Hetzer valve sizer evaluated according to the minimal age-related acceptable MV diameter, to avoid mitral stenosis. In both parachute and hammock valves, posterior annuloplasty reinforced with an untreated autologous pericardial strip (modified Paneth-Hetzer plication plasty) was also performed (Figure 2, B).

In addition to MV repair, 8 patients underwent concomitant closure of an atrial septal defect, 1 underwent patch closure of ventricular septal defect, another underwent a Ross procedure, and 3 underwent concomitant tricuspid annuloplasty.

Intraoperative surgical valve analysis was performed by saline injection through the valves, and intraoperative transesophageal echocardiography scans were routinely performed to assess the adequacy of repair, with particular attention to the leaflet mobility. After MV repair, the diastolic mitral inflow, as assessed by continuous flow Doppler echocardiography, was a mean of $2.81 \pm 0.58 \mathrm{~mm} \mathrm{Hg}$. In all the repair strategies we used, the minimal final MV opening area should not be less than $10 \%$ below the norm according to the body surface area in the children. We are cautious to avoid the occurrence of the systolic anterior motion phenomenon, seen as "folding" of the anterior leaflet when the valve opening is made too narrow by overreduction of the posterior annulus, seen when the valve is tested with saline instillation into the ventricle. ${ }^{10}$ Postoperative transthoracic echocardiography was performed annually, or if clinically indicated, on the basis of symptoms. The degree of MI was estimated by standard echocardiographic measurement techniques, as previously described in the "Patients and Methods" section. Regardless of the underlying pathologic findings and techniques used, no patient was discharged from the hospital with more than mild MI.

\section{Follow-up}

The follow-up data were provided by both the Department of Congenital Heart Disease/Pediatric Cardiology and the Department of Clinical Studies, Deutsches Herzzentrum Berlin and by written correspondence from the referring physicians. No patients were lost to follow-up. The end of the follow-up period was December 2010.

\section{Statistical Analysis}

All data were analyzed using the Statistical Package for Social Sciences, version 16.0 (SPSS, Chicago Ill) software program. The data are expressed as the absolute and percentage frequency values and continuous data as the mean \pm standard deviation, as appropriate. The repeated measurements of echocardiographic variables in serial timelines, were analyzed using the Friedman tests. A value of $P \leq .05$ was considered significant. The freedom from reoperation was analyzed according to the Kaplan-Meier estimates with $95 \%$ confidence intervals.

\section{RESULTS}

\section{Clinical, Functional, and Echocardiographic Results}

Postoperatively and on serial follow-up, all patients had a tremendous abatement of the MI, with a mean mitral inflow gradient of $2.81 \pm 0.58 \mathrm{~mm} \mathrm{Hg}$ (the acceptable maximal gradient in children is set at $3.5 \mathrm{~mm} \mathrm{Hg}$ ), and all had functionally improved from New York Heart Association class III to class I. The early postoperative morbidity was arrhythmia, which converted to a sinus rhythm with temporary pacing within 48 hours, in 1 patient. No early mortality occurred. Two reoperations were required within 1 year after the initial repair. One was a female child aged 2 years, 1 month at the initial MV repair for severe MI (grade IV). The intraoperative findings included a markedly dilated annulus, with thickened leaflets, but without any 
A
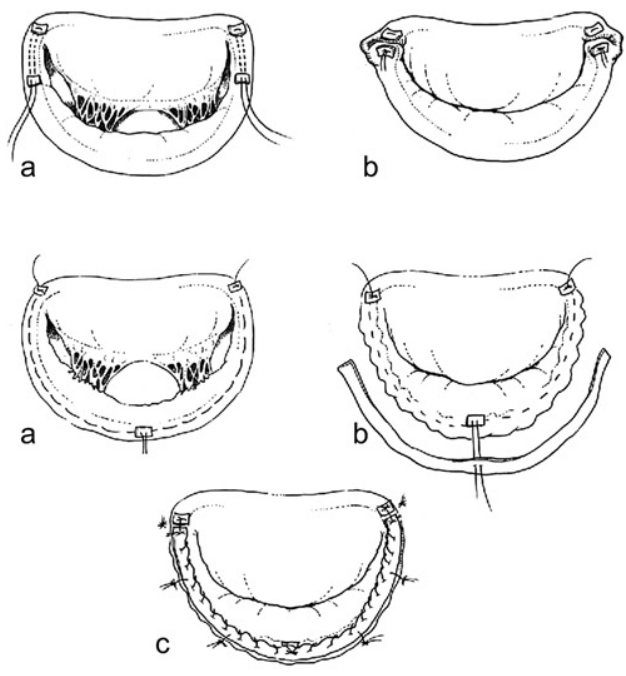

B

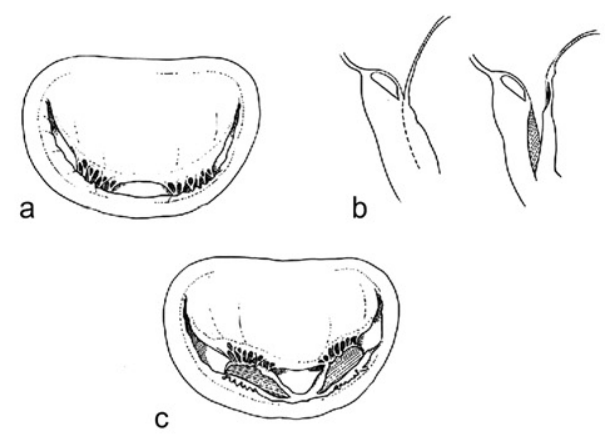

C

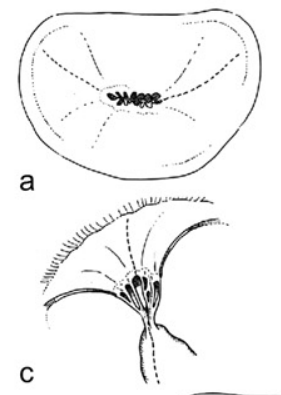

C
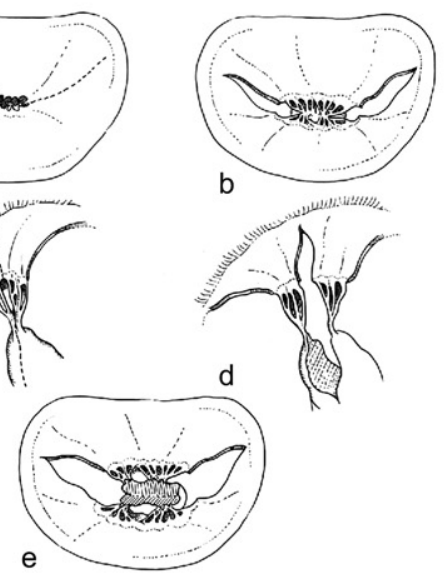

b

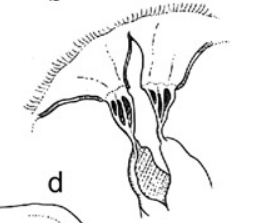

D

FIGURE 2. Mitral valve $(M V)$ repair techniques. A, part a, Modified KayWooler annuloplasty with Hetzer's modification. A, part b, Completed repair. B, part a, Modified Paneth-Hetzer posterior annulus shortening plasty. B, part b, Reinforcement with autologous pericardial strip. B, part c, Completed repair. C, Hammock valve. C, part a, Prerepair. C, part b, Splitting off papillary muscle from posterior ventricular wall. C, part c, After repair. D, Parachute valve. D, part a, Prerepair. D, part b, Commissurotomy and fenestration. D, parts c and d, Commissurotomy and splitting of papillary muscles. D, part e, Completed repair. structural defects of the subvalvar apparatus. Modified Paneth-Hetzer annuloplasty was performed. After the repair, the MV orifice was measured to be $16 \mathrm{~mm}$, which was normal (a patient with a body surface area of 0.48 $\mathrm{m}^{2}$ should have a $16-\mathrm{mm}$ annular diameter, according to the nomogram of Rowlatt and colleagues ${ }^{11}$ ), and she was discharged free of any MI. However, she underwent repeat MV repair 11 months later because of progressive impairment of functional capacity and progression of MI 9 months before the repeat surgery. Intraoperatively, the mitral annulus was markedly dilated and the anterior mitral leaflet and commissural portion of the posterior annulus were noted to be enlarged. The pericardial strip with the plication sutures was perfectly attached to the posterior annulus and covered by a layer of fibrous tissue without calcification remaining in the central portion of the posterior mitral annulus. The anterior mitral leaflet was noted to be slightly thickened, pliable, and freely mobile. The MV orifice was measured at $18 \mathrm{~mm}$, and the mitral annular diameter was $20 \mathrm{~mm}$. At the latter surgery, in addition to the modified Paneth-Hetzer annuloplasty, a Kay-Wooler commissural plication annuloplasty of the posteromedial commissure was performed. Another patient who was 3 years old at the initial MV repair for congenital MI with an extremely dilated annulus and thickened leaflets, developed a markedly high-pressure gradient of $30 \mathrm{~mm} \mathrm{Hg}$ across the MV, had associated aortic valve regurgitation, and functionally deteriorated. She underwent mechanical valve replacement 8 months after the initial valve repair. During reoperation, the leaflets were severely retracted without any coaptating potential; however, each pericardial strip appeared completely endothelialized and was indistinguishable from the atrial endocardium. One patient (2 years old at the initial MV repair) with a parachute valve underwent MV replacement 2 years after the initial repair. She died 8 years later of noncardiac causes. In all other subsequent reoperations during the course of follow-up, the pericardial strip appeared intact and perfectly integrated with the annular tissues.

\section{Follow-up}

The mean duration of follow-up was $11.2 \pm 7.2$ years (median, 11.28; range, 6 months to 23.7 years). The freedom from reoperation rate was $100 \%$ at 30 days and $95.7 \% \pm 3.0 \%, 86.0 \% \pm 5.3 \%, 79.6 \% \pm 6.6 \%$, and $71.1 \% \pm 8.1 \%$ at $1,5,10,15$, and 20 years, respectively. Stratified by age group at the initial repair, the freedom from reoperation rate was $100 \%$ at 30 days in all age group. For those younger than 1 year old, the freedom from reoperation rate was $100 \%$ at 1 year and $57.1 \% \pm$ $8.7 \%$ at 5 and 20 years. The freedom from reoperation rate was $90.9 \% \pm 6.1 \%$ at 1 and 5 years, $78.8 \% \pm$ $9.6 \%$ at 10 years, and $63.2 \% \pm 12.6 \%$ at 15 years in those older than 1 to 5 years. The freedom from reoperation rate 
was $100 \%$ at 1 year and $90.9 \% \pm 8.7 \%$ at $5,10,15$, and 20 years in those aged 6 to 12 years. No reoperations were performed in those children older than 13 years old at the initial repair. The cumulative survival rate was $100 \%$ at 30 days, 1 year, and 5 years and $96.9 \% \pm 3.6 \%$ at 10,15 , and 20 years.

\section{DISCUSSION}

It is extremely challenging to reconstruct MVs in infants and children, primarily because the leaflets and subvalvar apparatus are small, immature, and fragile. In congenital MI from restricted leaflet motion, one might be tempted to resect the tissues and reconstruct it with prosthetic rings, or to simply replace the valve, to restore the mitral competence. Various techniques from various investigators and institutions have evolved to correct the problem. ${ }^{2,13-24}$ In this population, however, ring annuloplasty would disturb the growth of the MV along its anterior annulus. Valve replacement poses clinical and technical difficulties because of a small-size annulus, left atrium, and left ventricle, along with accelerated tissue calcification and degeneration of the bioprosthesis, and lifetime anticoagulation. In addition, no suitably size prosthesis is available for this age group, and re-replacement of the prosthesis with the growth of the child is inevitable. No exclusive report has been published on restoring mitral competence in congenital MV lesions secondary to restricted leaflet motion using suture repair techniques with posterior annulus stabilization and untreated autologous pericardial strips.

In deciding to repair the MV with restricted leaflet motion, our primary aim was to achieve a complete and rapid closure of the mitral orifice by a well-mobile anterior leaflet with a sufficiently large coaptation area by bringing the posterior leaflet closer to the anterior leaflet. Primary repair was achieved with sutures only. The pericardial strip did not lead to additional annulus shortening, but stabilized the suturedependent repair and increased the height of the posterior leaflet coaptation surface area. Moreover, we believe that suture repair techniques for congenital MI allows undisturbed somatic and valve growth, ${ }^{7,8}$ delays the need for future valve replacement, and avoids anticoagulation. The stabilization of repair with an autologous pericardial strip allows the MV to grow along the anterior annulus. No calcification, shrinkage, infection, or thrombus formation on the pericardial strip has developed. On reoperation, the pericardium was seen to be completely endothelialized, perfectly integrated into the annular tissue, and completely indistinguishable from the atrial endocardium. Modifications in repair techniques and the routine use of intraoperative transesophageal echocardiography to assess the adequacy of the repair has contributed significantly to the success of MV repair as the surgical management for MI from restricted leaflet motion in children. Our freedom from repeat MV reconstruction and freedom from MV replacement at more than 20 years of follow-up is highly satisfactory.

\section{CONCLUSIONS}

Surgical reconstruction for MI from MV lesions with restricted leaflet motion in infants and children was performed using various suture repair techniques and strategies, with excellent functional results and a low reoperation rate at more than 20 years of follow-up. These techniques, which restored the mitral competence with effective functioning of the remodeled valve and the preservation of the natural shape of the valve, at the same time allowing the valve to grow as the patient grows older, are useful surgical tools for MV reconstructive surgery in infants and children. Shortening the posterior annulus produces a wide and even coaptation, such that the posterior leaflet is brought closer to the anterior leaflet. Thus, when the anterior mitral leaflet closes, the border between the smooth and rough surface of the anterior leaflet forms the closure line, without folding. Stabilization of the posterior annulus with a pericardial strip prevents additional posterior annular dilation and allows the anterior MV leaflet and its annulus to grow in relation to the patient's body size, as well as preserving the flexible properties of the MV orifice.

We greatly appreciate the assistance of Christine Detschades, Julia Stein, Astrid Benhennour Helge Haselbach, and Mariano Francisco del Maria Javier. We thank Anne Gale, medical editor, for assistance with our report.

\section{References}

1. Uva MS, Galletti L, Gayet FL, Piot D, Serraf A, Bruniaux J, et al. Surgery for congenital mitral valve disease in the first year of life. J Thorac Cardiovasc Surg. 1995;109:164-76

2. Chauvaud S, Fuzellier JF, Houel R, Berrebi A, Mihaileanu S, Carpentier A. Reconstructive surgery in congenital mitral valve insufficiency (Carpentier's techniques): Long-term results. J Thorac Cardiovasc Surg. 1998;115:84-93.

3. Ohno H, Ihmai Y, Terada M, Hiramatsu T. The long-term results of commissure plication annuloplasty for congenital mitral insufficiency. Ann Thorac Surg. 1999;68:537-41.

4. McCarthy JF, Nelligan MC, Wood AE. Ten years' experience of an aggressive reparative approach to congenital mitral valve anomalies. Eur J Cardiothorac Surg. 1996;10:534-9.

5. Zias EA, Mavroudis C, Backer CI, Kohr LM, Gotteiner NI, Rocchini AP. Surgical repair of the congenitally malformed mitral valve in infants and children. Ann Thorac Surg. 1998;66:1551-9.

6. Sugita T, Ueda Y, Matsumoto M, Ogino H, Nishihawa J, Matsuyama K. Early and late results of partial placation annuloplasty for congenital mitral insufficiency. J Thorac Cardiovasc Surg. 2001;122:229-32.

7. Komoda T, Huebler M, Berger F, Hetzer R. Growth of mitral annulus in the pediatric patient after suture annuloplasty of the entire posterior mitral annulus. Interact Cardiovasc Thorac Surg. 2009;9:354-6.

8. Delmo Walter EM, Siniawski H, Ovroutski S, Hetzer R. Mitral valve growth after posterior annular stabilization with untreated autologous pericardial strip in children with mitral valve insufficiency. Ann Thorac Surg. 2010;90:1577-85.

9. Siniawski H, Huebler M, Amiri A, Yankah CA, Hetzer R. Perioperative imaging of mitral valve incompetence. In: Hetzer R, Rankin JS, Yankah CA, eds. Mitral Valve Repair: The Biological Solution. Berlin: Springer Verlag; 2011. p. 4-24.

10. Hetzer R, Delmo Walter EM. Repair of congenital mitral valve insufficiency. $O p$ erat Techn Thorac Cardiovasc Surg. 2010;15:260-72.

11. Rowlatt U, Rimoldi H, Lev M. The quantitative anatomy of the normal child's heart. Pediatr Clin North Am. 1963;10:499-588. 
12. Hetzer R, Delmo Walter EMB, Huebler M, Alexi-Meskishvili V, Weng Y, Nagdyman N, et al. Modified surgical techniques and long term outcome of mitral valve reconstruction in 111 children. Ann Thorac Surg. 2008;86:604-13.

13. Carpentier A. La valvuloplaste reconstitutive. Une nouvelle technique de valvuloplastie mitrale. Presse Med. 1969;77:251-3.

14. Carpentier AF, Lessana A, Relland JY, Belli E, Mihaileanu S, Berrebi AJ, Palsky E, Loulmet DF. The "physio-ring": An advanced concept in mitral valve annuloplasty. Ann Thorac Surg. 1995;60:1177-85.

15. Duran CG, Ubago JL. Clinical and hemodynamic performance of a totally flexible prosthetic ring for atrioventricular reconstruction. Ann Thorac Surg. 1976; 22:458-63.

16. Cooley DA, Frazier OH, Norman JC. Mitral leaflet prolapse: Surgical treatment using a posterior annular collar prosthesis. Cardiovasc Dis. 1976;3:438-43.

17. Sousa UM, Gallenti L, Lacour-Gayet F, Piot D, Seraf A, Brumiax J, Comas J, Roussin R, Touchot A, Binet JP, Planche C. Surgery for congenital mitral valve disease in the first year of life. J Thorac Cardiovasc Surg. 1995;109:164-76.

18. Stellin G, Padalino M, Milanesi O, Vida V, Favaro A, Rubino M, Bifafanti R, Casarotto D. Repair of congenital mitral valve dysplasia in infants and children: Is it always possible? Eur J Cardiothorac Surg. 2000;18:74-82.
19. Prifti E, Vanini V, Bonacchi M, Frati G, Bernabei M, Giunti G, et al. Repair of congenital malformations of the mitral valve: Early and midterm results. Ann Thorac Surg. 2002;73:614-21.

20. Pellegrini A, Quaini E, Colombo T, Lanfranchi M, Russo C, Vitali E. Posterior annuloplasty in the surgical treatment of mitral insufficiency. J Heart Valve Dis. 1993;2:633-8.

21. Chauvaud SM, Mihaileanu SA, Gaer JAR, Carpentier A. Surgical treatment of mitral valvar insufficiency. Cardiol Young. 1997;7:5-14.

22. Wood AE, Healy DG, Nolke L, Duff D, Oslizlok P, Walsh K. Mitral valve reconstruction in pediatric population: Late clinical results and predictors of long outcome. J Thorac Cardiovasc Surg. 2005;130:66-73.

23. Myers PO, Christenson JT, Cikirikcioglu M, Tissot C, Aggoun Y, Kalangos A. Leaflet suspension to the contralateral annulus to address restriction or tethering-induced mitral and tricuspid regurgitation in children: Results of a case-control study. J Thorac Cardiovasc Surg. 2010;140:1110-6.

24. Oppido G, Davies B, McMullan DM, Cochrane AD, Cheung MM d'Udekem Y, et al. Surgical treatment of congenital mitral valve disease: Midterm results of a repair-oriented policy. J Thorac Cardiovasc Surg. 2008;135: 1313-21. 